\title{
Malignant Transformation of Recurrent Meningioma with Pulmonary Metastases
}

\author{
Daniel R. LeMay, B.S., Michael N. Bucci, M.D., and S. M. Farhat, M.D. \\ Department of Surgery, Section of Neurosurgery, The University of Michigan and Catherine McAuley Health Center
}

LeMay DR, Bucci MN, Farhat SM. Malignant transformation of recurrent meningioma with pulmonary metastases. Surg Neurol $1989 ; 31: 365-8$.

A patient presented with a histologically benign intracranial meningioma which, after multiple recurrences, underwent malignant transformation. The patient survived 18 years following initial presentation. Pulmonary metastases were present over the final 8 years. Eleven subtotal resections of the meningioma were performed, including exenteration of the right eye and a thoracotomy. Radiation therapy and chemotherapy were relatively ineffective. The problem and treatment of recurrent meningiomas is briefly reviewed.

KEY WORDS: Meningioma; Metastasis; Pulmonary meningioma; Tumor recurrence

\section{Introduction}

Meningiomas are usually slow growing benign intracranial neoplasms. Complete surgical resection is often curative but may not be feasible based on factors such as extent, location, and bony or dural infiltration of the lesion. Recurrence is a continuing risk with subtotal resection, and even when resection is thought to be complete. Recurrent meningiomas can be difficult to control, often requiring multiple surgical resections. When repeated operations are required the chance of cure is significantly reduced [20]. In rare instances a histological malignant transformation may occur with the added risk of metastases.

We report on a case of a sphenoid wing meningioma which at the time of presentation was histologically benign. Location and bony infiltration resulted in subtotal resection with later recurrences. There was a histological malignant transformation following multiple surgical resections. Pulmonary metastases eventually led to the demise of the patient.

Address reprint requests to: S. M. Farhat, M.D., Section of Neurosurgery, 5333 McAuley Avenue, Suite R3112, Reichert Health Building, Ypsilanti, Michigan 48197.

Received June 27, 1988; accepted September 22, 1988.

\section{Case Report}

A 56-year-old nonsmoking right-handed woman was first seen in February 1967, with a 3-year history of right temporal headaches, episodes of dizziness, and an unsteady gait. Two months prior to admission she became aware of a nontender progressively enlarging right temporal mass.

Examination revealed a $4 \times 5 \mathrm{~cm}$ hard mass in the right temporal zygomatic area. Skull $x$-rays, nuclear brain scan, and cerebral angiography confirmed the presence of a large tumor mass in the right anterior and middle cranial fossa. The chest $\mathrm{x}$-ray was normal.

In February 1967, the patient underwent a right temporal craniotomy with partial resection of an intracranial sphenoid wing meningioma. The tumor involved the temporal bone, sphenoid wing, and dura. Bony infiltration of the sphenoid wing prevented total resection.

Two years later the patient returned with recurrence of the right zygomatic mass, and a second resection was performed. Over the next 16 years the tumor involved adjacent structures, requiring exenteration of the right orbital contents and resection of tumor from the zygoma, periorbital region, and the angle of the mandible. The tumor appeared to dissect along tissue planes without invading muscle or fascia.

In 1977 a solitary right pulmonary nodule was noted (Figure 1). In 1982 multiple pleural and parenchymal lesions were identified in the right lung field, and then resected through a right thoracotomy. Following this operation 5,250 rads of radiation were given to the right orbital and temporal region. Radiation slowed the development of additional facial tumors but pulmonary lesions recurred along with incapacitating shortness of breath. In 1984 a course of chemotherapy with cytoxin, adriamycin, and vincristine was ineffective. Shortly before the patient's death in 1985 , radiation to the right chest and right mandible was carried out with minimal benefit.

Histological examination of hematoxylin and eosinstained paraffin sections demonstrated that the primary tumor (1967) was a benign meningioma (Figure $2 \mathrm{~A}$ ). 


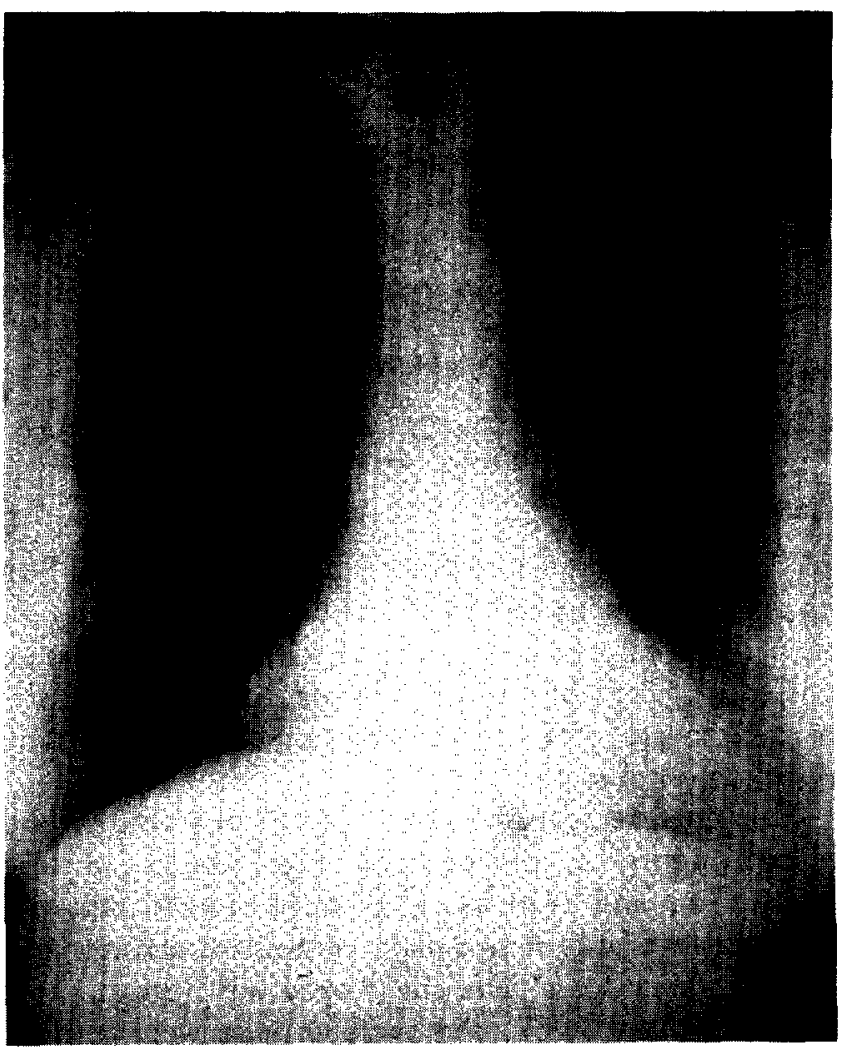

Figure 1. Chest roentgenogram posteroanterior view. In 1967 a solitary round intraparenchymal mass was identified in the right lung field (arrow).

Specimens from 1969 showed the first signs of rare mitoses but were generally benign. In 1975 there was increasing nuclear atypia (Figure 2 B), and by 1977 mitoses, nuclear atypia, and cellular pleomorphism had increased enough to imply a malignant transformation (Figure $2 \mathrm{C}$ ). In 1982 fifteen pulmonary nodules were resected which showed malignant changes, containing increased numbers of mitoses, cellularity, and pleomorphism (Figure 3). Resection 3 days earlier of the recurrent primary neoplasm in the periorbital region revealed an identical histology.

\section{Discussion}

Metastasis of meningiomas to distant extracranial sites is uncommon. There have been approximately 113 cases of metastasizing meningiomas reported [1,2,9$12,14,15,18,19,21]$. If the more often aggressive pericytic and "angioblastic" types are excluded, there have been approximately 69 cases of meningiomas with extracranial metastases reported in the literature from 1886 to 1986.

The majority of meningiomas are benign. Even when they show malignant histological features, metastases are uncommon. Malignant histology is more often expressed as infiltrating rapid growth which increases the risk of local recurrences following surgical resection. Local recurrence not only complicates the control of the neoplasm, but also dramatically increases the morbidity of the patient. Cushing and Eisenhardt [8] came to appreciate the potential for local recurrence of meningiomas. Simpson [20] addressed the problem of recurrence (the return of symptoms due to tumor growth following a period of symptomatic relief), estimating an overall incidence of recurrence of $21 \%$ in 235 cases. He proposed a five-level grading system based on the relative completeness of surgical removal of the tumor. As expected, the incidence of recurrence increased markedly for incomplete resections. Even after complete surgical removal there was still a high recurrence rate $(9 \%)$. It is difficult to determine if a recurrence will occur. Some studies have correlated histopathologic features with recurrence $[4,13,16]$, while in addition, the role of regional multicentricity may be important with gross "total" resection of the tumor $[5,6]$.

Treatment options for local recurrences include 1) more radical resection, 2) palliative subtotal resections, 3) radiation therapy, and 4) chemotherapy. More radical resection may be justified in an attempt to eradicate the tumor and reduce the likelihood of additional recurrence. Simpson [20] reported favorable results with this approach in spite of higher surgical risk. More often the surgeon is limited by the location of the neoplasm and the extent of invasion. Subsequent subtotal resection can provide palliative relief when a radical operation would endanger the patient, but there is a greater risk for repeated recurrences. In addition, a rare but important risk associated with recurrence is malignant transformation with possible metastasis. In any case, recurrence dramatically increases patient morbidity. The detailed description by Cushing and Eisenhardt [8] of the agonizing course endured by Dorthy May Russell who underwent 17 operations over 18 years was unfortunately similar to our patient who underwent 11 operations during an equivalent time period.

Alternative nonsurgical treatment of recurrent meningiomas has been employed. While some studies have shown limited effects of radiation therapy [20,22], there is increasing evidence to indicate that radiation therapy is beneficial in the treatment of recurrent meningiomas $[3,7,17,23]$. In our patient the rate of tumor growth was decreased but radiation therapy was used late in course of the disease and the end result was not changed. Chemotherapy is rarely employed and the use of cytoxin, adriamycin, and vincristine in this patient had little effect on the tumor.

The majority of reported metastatic meningiomas had malignant histological characteristics at the time of 

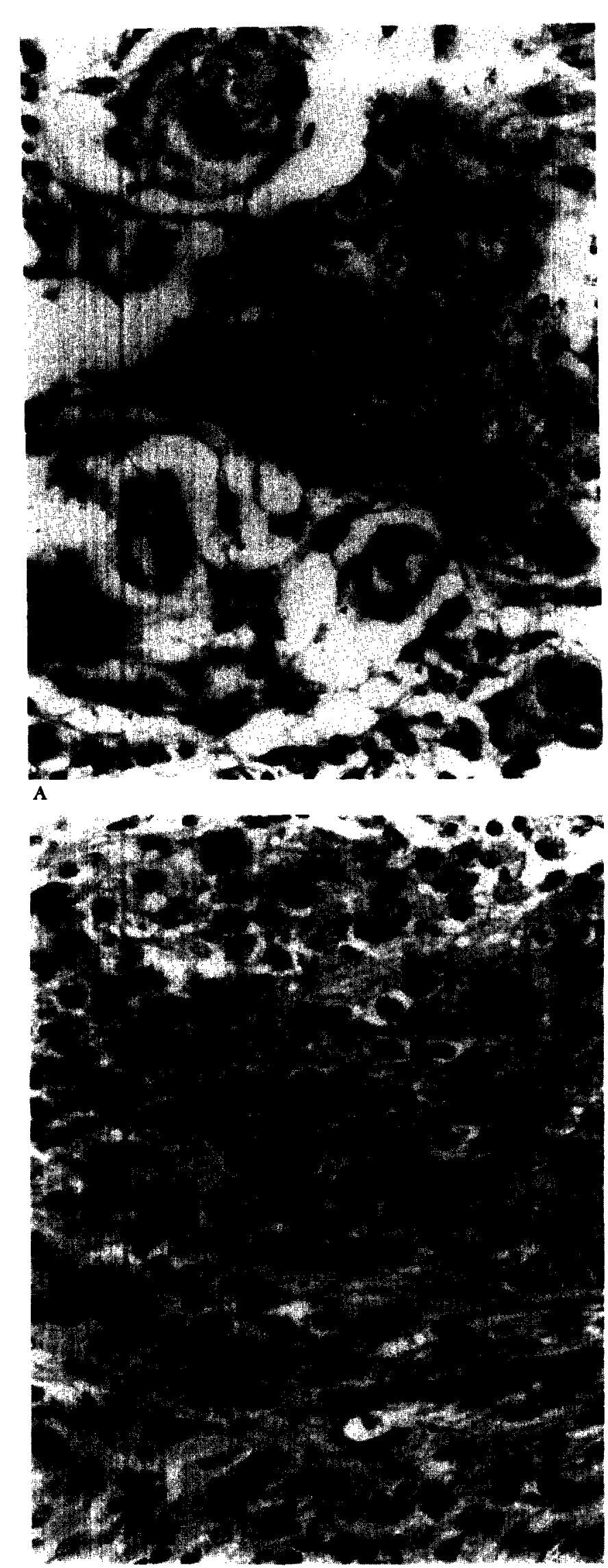

B

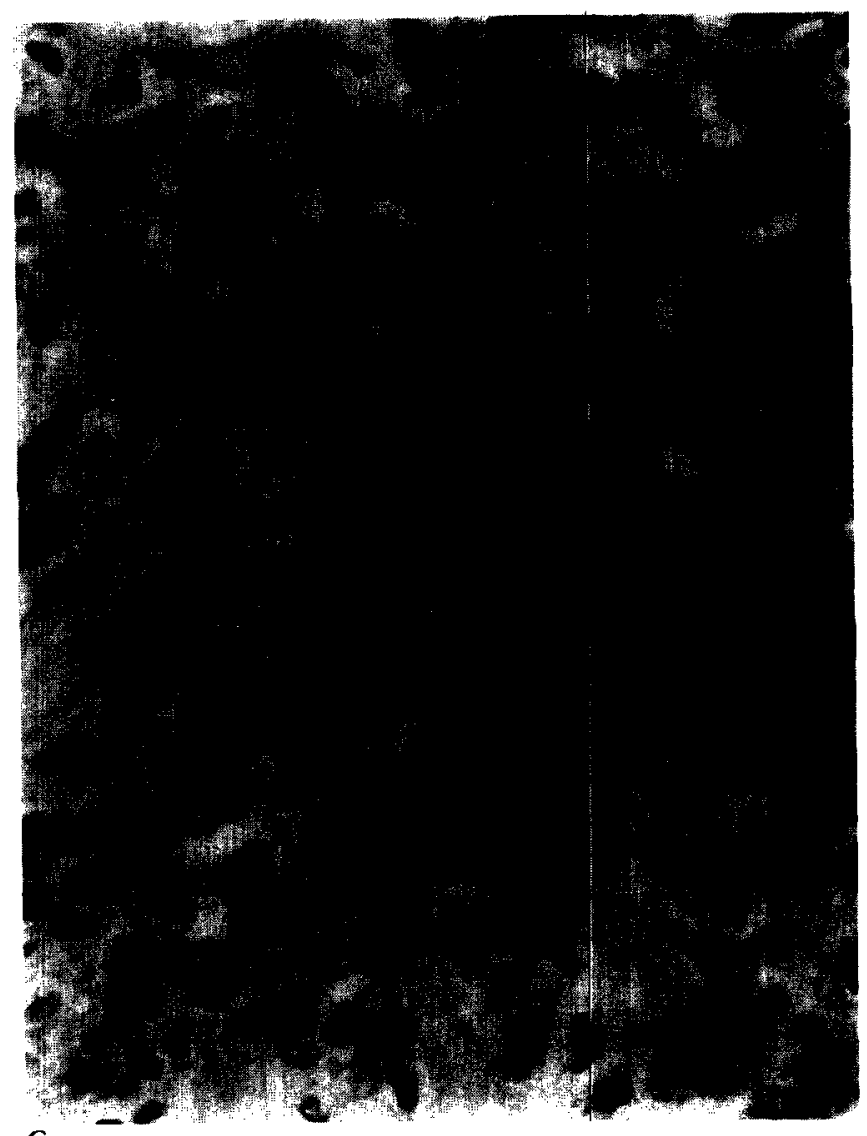

C

Figure 2. Photomicrographs of neoplasm. (A) 1967 tissue section of the primary intracranial meningioma demonstrating a benign meningotheliomatous pattern with whorls $(H E E \times 300)$. (B) 1975 tissue section of recurrent primary neoplasm with mild nuclear atypia (HEE $\times 300)$. (C) 1977 tissue section showing increased atypia and pleomorphism (HEE $\times$ 300).

presentation. In three exceptional cases $[14,15,19]$ both the primary and the metastases were believed to be completely benign. Three additional cases were reported as benign meningioma in the primary and as metastases but without histologic documentation [21]. In two other cases metastases were benign while a recurrence of the primary had a sarcomatous pattern [18] or malignant appearance [2]. These special cases have led to the awkward designation of "benign" metastases. In our case the initial presentation of the meningioma in 1967 was benign. Tissue samples from the recurrent primary in 1975 showed the first sign of malignant potential. In 1977 a solitary nodule was noted in the right lung field. We cannot rule out the possibility that the preceding craniotomies led to an inadvertent seeding of the tumor into the blood stream resulting in the pulmonary metastasis. Of particular interest was the 


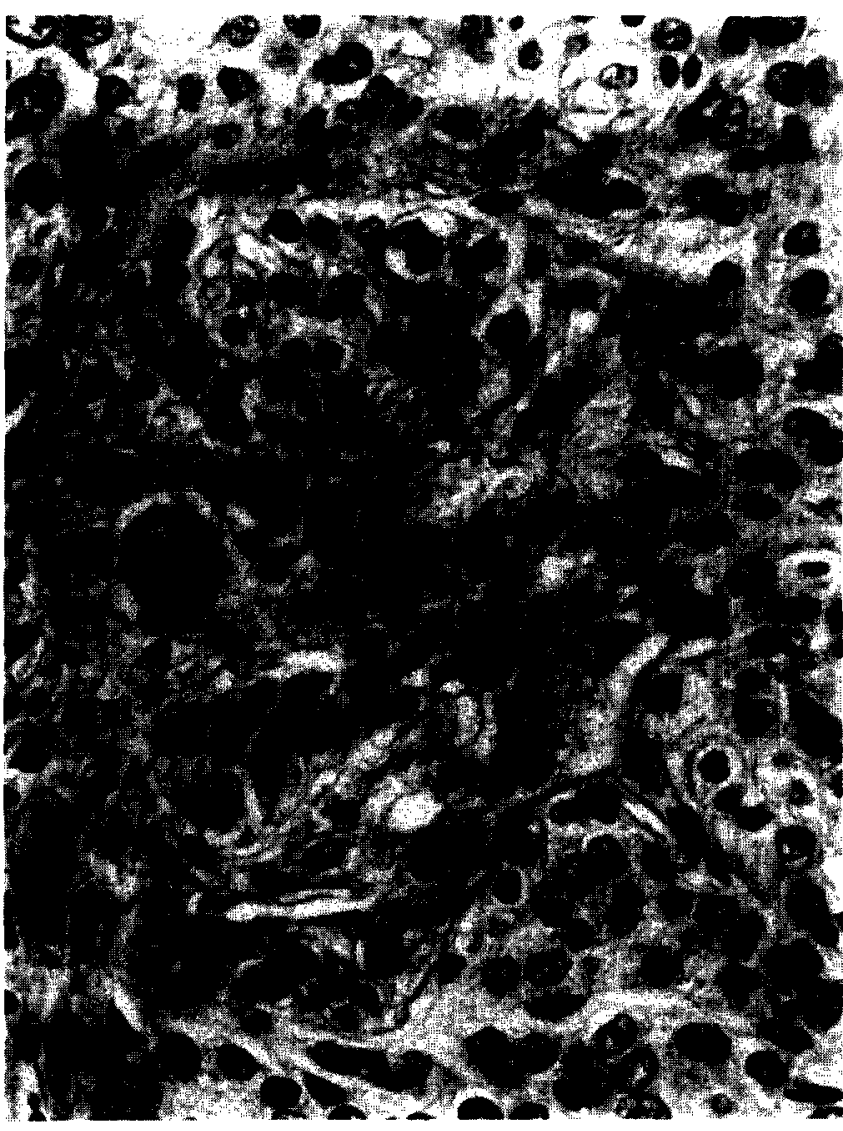

Figure 3. Photomicrograph of neoplasm. 1982 pulmonary metastasis showing increased mitotic activity, cellularity, and pleomorphism (HEE $\times$ 300).

slow rate of growth of the lung nodule $(50 \%$ increase in size by 1980) as compared to the rapid recurrence rate of the primary. Considering its slow rate of growth the lung metastasis may have had a benign histology initially, while the recurrent primary had already undergone a malignant transformation, as in the cases of Repola and Weatherbee [18] and Arnould et al [2].

Alternatively, the lung metastasis may have resulted from cells which had already undergone a malignant histological transformation. In our case there is no histological documentation of the lung metastasis at the time of initial presentation and, therefore, the question of "benign" versus malignant metastasis cannot be addressed. An important point made is metastasis of meningiomas may not require histological malignancy.

We thank Dr. John J. Kepes for his generous help and for reviewing the histological slides pertinent to this case, and Dr. Manfred $\mathrm{H}$. Soiderer for his assistance in preparing the photomicrographs. We greatly appreciate the editorial assistance of Dr. Julian T. Hoff and Dr. William F. Chandler.

\section{References}

1. Abbott $\mathrm{KH}$, Love JG. Metastasizing intracranial tumors. Ann Surg 1943;118:343-52.

2. Arnould G, Lepoire J, Pierson B, Barrucand D. Les meningiomes malins. (A propos d'une observation.) Rev Neurol 1961;105:469-79.

3. Barbaro NM, Gutin PH, Wilson CB, Sheline GE, Boldrey EB, Wara WM. Radiation therapy in the treatment of partially resected meningiomas. Neurosurgery 1987;20:525-8.

4. Boker DK, Muerer H, Gullotta F. Recurring intracranial meningiomas. Evaluation of some factors predisposing for tumor recurrence. J Neurosurg Sci 1985;29:11-7.

5. Borovich B, Doron Y. Recurrence of intracranial meningiomas: the role played by regional multicentricity. J Neurosurg 1986;64:58-63.

6. Borovich B, Doron Y, Braun J, Guilburd JN, Zaaroor M, Goldsher D, Lemberger A, Gruszkiewicz J, Feinsod M. Recurrence of intracranial meningiomas: the role played by regional multicentricity. Part 2: clinical and radiological aspects. J Neurosurg 1986;65:168-71.

7. Carella RJ, Ransohoff J, Newall J. Role of radiation therapy in the management of meningioma. Neurosurgery 1982;10:332-9.

8. Cushing $\mathrm{H}$, Eisenhardt L. Meningiomas: Their classification, regional behavior, life history, and surgical end results. Springfield, IL: Charles C. Thomas, 1938.

9. Hoffman GT, Earle KM. Meningioma with malignant transformation and implantation in the subarachnoid space. J Neurosurg 1960;17:486-92.

10. Jurow HN. Psammomatous dural endothelioma (meningioma) with pulmonary metastasis. Arch Pathol 1944;37:216-8.

11. Karasick JL, Mullen SF. A survey of metastatic meningiomas. J Neurosurg 1974;40:206-12.

12. Kepes JJ. Meningiomas: Biology, pathology, and differential diagnosis. New York: Masson, 1982:190-9.

13. Kepes JJ. Presidential Address: The histopathology of meningiomas. A reflection of origins and expected behavior. J Neuropath Exp Neurol 1986;45:95-107.

14. Kruse F Jr. Meningeal tumors with extracranial metastasis. A clinicopathologic report of 2 cases. Neurology 1960;10:197201.

15. Miller DC, Ojemann RG, Proppe KH, McGinnis BD, Grillo HC. Benign metastasizing meningioma. J Neurosurg 1985; 62:763-6.

16. Monte SM, Flickinger J, Linggood RM. Histopathologic features predicting recurrence of meningiomas following subtotal resection. Am J Surg Pathol 1986;10:836-43.

17. Petty AM, Kun LE, Meyer GA. Radiation therapy for incompletely resected meningiomas. J Neurosurg 1985;62:502-7.

18. Repola D, Weatherbee $\mathrm{L}$. Meningioma with sarcomatous change and hepatic metastasis. Arch Pathol Lab Med 1976;100:667-9.

19. Ringsted J. Meningeal tumors with extracranial metastasis, with a case report. Acta Pathol Microbiol (Scand) 1958;43:9-20.

20. Simpson $D$. The recurrence of intracranial meningiomas after surgical treatment. J Neurol Neurosurg Psychiatry 1957;20:2239.

21. Som PM, Sacher M, Strenger SW, Biller HF, Malis LI. "Benign" metastasizing meningiomas. AJNR 1987;8:127-30.

22. Thomas HG, Dolman CL, Berry K. Malignant meningioma: clinical and pathological features. J Neurosurg 1981;55:929-34.

23. Wara WM, Sheline GE, Newman H, Townsend JJ, Boldrey EB. Radiation therapy of meningiomas. AJR 1975;123:453-8. 